\title{
A comparison of sexual risk behaviours and HIV seroprevalence among circumcised and uncircumcised men before and after implementation of the safe male circumcision programme in Uganda
}

Simon Peter Sebina Kibira ${ }^{1,2^{*}}$, Ingvild Fossgard Sandøy ${ }^{1}$, Marguerite Daniel ${ }^{3}$, Lynn Muhimbuura Atuyambe ${ }^{2}$ and Fredrick Edward Makumbi ${ }^{4}$

\begin{abstract}
Background: Although male circumcision reduces the heterosexual HIV transmission risk, its effect may be attenuated if circumcised men increase sexual risk behaviours (SRB) due to perceived low risk. In Uganda information about the protective effects of circumcision has been publicly disseminated since 2007. If increased awareness of the protection increases SRB among circumcised men, it is likely that differences in prevalence of SRB among circumcised versus uncircumcised men will change over time. This study aimed at comparing SRBs and HIV sero-status of circumcised and uncircumcised men before and after the launch of the safe male circumcision programme.

Methods: Data from the 2004 and 2011 Uganda AIDS Indicator Surveys (UAIS) were used. The analyses were based on generalized linear models, obtaining prevalence ratios (PR) as measures of association between circumcision status and multiple sexual partners, transactional sex, sex with non-marital partners, condom use at last non-marital sex, and HIV infection. In addition we conducted multivariate analyses adjusted for sociodemographic characteristics, and the multivariate models for HIV status were also adjusted for SRB.

Results: Twenty six percent of men were circumcised in 2004 and $28 \%$ in 2011. Prevalence of SRB was higher among circumcised men in both surveys. In the unadjusted analysis, circumcision was associated with having multiple sexual partners and non-marital partners. Condom use was not associated with circumcision in 2004, but in 2011 circumcised men were less likely to report condom use with the last non-marital partner. The associations between the other sexual risk behaviours and circumcision status were stable across the two surveys." In both surveys, circumcised men were less likely to be HIV positive (Adj PR 0.55; Cl: 0.41-0.73 in 2004 and Adj PR 0.64; Cl: $0.49-0.83$ in 2011)

(Continued on next page)
\end{abstract}

\footnotetext{
* Correspondence: pskibira@gmail.com

${ }^{1}$ Centre for International Health, Department of Global Public Health and

Primary Care, Faculty of Medicine and Dentistry, University of Bergen, Bergen,

Norway

${ }^{2}$ Department of Community Health and Behavioural Sciences, School of

Public Health, Makerere University, Kampala, Uganda

Full list of author information is available at the end of the article
} 
(Continued from previous page)

Conclusions: There was higher prevalence of SRBs among circumcised men in both surveys, but the only significant change from 2004 to 2011 was a lower prevalence of condom use among the circumcised. Nevertheless, HIV prevalence was lower among circumcised men. Targeted messages for circumcised men and their sexual partners to continue using condoms even after circumcision should be enhanced to avoid risk compensation.

Keywords: Circumcision, Condom use, Survey, Sexual risk behaviours, HIV, Multiple partners, Non-marital sex, Uganda

\section{Background}

Heterosexual transmission of HIV is still the biggest contributor to the HIV epidemic in sub Saharan Africa where over $70 \%$ of the estimated global 35 million HIV positive people live [1, 2]. Male circumcision reduces HIV heterosexual transmission risk from infected women to men [3-8], prevalence of high risk human papilloma virus and incidence of Herpes simplex virus two in men and, genital ulcers in female partners of circumcised HIV negative men [9-12]. In 2007, male circumcision was recommended in 14 sub Saharan African countries with high HIV prevalence but low levels of male circumcision [13, 14].

The Ministry of Health and partners in Uganda have scaled up circumcision through the national safe male circumcision (SMC) programme since 2007. Health workers were provided with accurate information using flip charts and question-answer booklets to assist clients, while media training sessions equipped journalists with information about SMC and its link to HIV prevention. The general public was educated through radio and television talk shows, newspaper columns and educational materials such as brochures for men [15]. A national policy guiding the programme was launched in 2010 [16] together with a national communication strategy [17]. In 2011, there were further social marketing efforts to increase demand, such as the "stand proud, get circumcised" campaign using a provocative approach that spoke to men through women. This was designed to convince men who had intentions of circumcision to get SMC services while encouraging women to support their partners to get circumcised and encouraging adherence to post circumcision practices that promote healing. The SMC intervention is implemented as an additional approach to the existing HIV prevention programmes such promoting condom use and being faithful to one sexual partner, and its demand and service provision increased. Between 2009 and September 2013, over 1.4 million adult men were circumcised $[18,19]$.

Male circumcision has the potential to reduce the HIV epidemic at population level with large scale benefits projected [20, 21]. There are concerns however that promoting such large scale population level interventions may also come with potential for behavioural risk compensation [22-25]. Circumcised men may as a result of reduced self-perceived risk to HIV and sexually transmitted infections increase sexual risk behaviours, including frequency of unprotected sex with multiple high risk partners [26-28], in part due to misperceptions from social marketing about the 'partial' protective effect of male circumcision [29]. Increases in sexual risk behaviours have been documented in Uganda among people living with HIV on antiretroviral therapy [30], partly due to reduced risk perception [31]. HIV vaccine trials have documented similar concerns with increases in sexual risk behaviours after vaccination among some groups [32-34].

Information from the three randomised controlled trials on which the $\mathrm{WHO}$ recommendation of the male circumcision intervention was mainly based, indicated both adjustments and non-adjustments in the sexual behaviour of participants. In South Africa [8] circumcised men reported more sexual partners in the 4-21 month recall periods post circumcision while in Kenya [7], inconsistent condom use declined in the control but not in intervention group after a 24 month period of repeated emphasis on comprehensive behaviour related counselling. In contrast, in the Ugandan trial $[6,35]$, there was no evidence of behavioural risk compensation reported even in follow up studies. However, the authors indicate in the study limitations that all the participants in these studies had received intensive health education and counselling during the trial period, and therefore such results may not be generalizable to the general male population who receive male circumcision through routine services.

There are few studies $[23,28,36-38]$ outside of the three trials that have examined the association between male circumcision and sexual risk behaviour. Our earlier analysis of differences in sexual risk behaviours in the 2011 Uganda AIDS indicator survey (UAIS) alone, showed higher odds of engaging in sexual risk behaviours among circumcised men than the uncircumcised [39]. However, no comparison with the period before the implementation of the national SMC programme (2004 UAIS) has been done. The objectives of this paper were to estimate whether there are differences in the associations between sexual risk behaviours and circumcision status, and HIV sero-status and circumcision status between the 2004 and 2011; the periods before and after 
implementing the SMC programme. We hypothesised a higher prevalence of sexual risk behaviours among circumcised men after information was made public that male circumcision offers partial protection from HIV.

\section{Methods}

\section{Study design and sampling procedures}

This study was based on data from two national surveys; the Uganda HIV/AIDS Sero-Behavioural Survey 2004 (which we refer to as UAIS in this paper) and the UAIS 2011. The 2004 UAIS was conducted before the implementation of the SMC programme while the 2011 UAIS was conducted after the SMC programme implementation was underway in the country. The two surveys have nationally representative samples obtained from stratified two-stage cluster sampling designs [40, 41]. In both surveys, clusters were selected from strata defined by urban/rural residence and geographical regions at the first stage, while the second stage involved selecting households for interview to obtain eligible respondents. Clusters were from a list of enumeration areas obtained from the 2002 Uganda population census (for the 2004 UAIS) and from the 2010 Uganda National Household Survey update of the 2002 Uganda population census (for the 2011 UAIS). At the first stage, 417 clusters in 2004 and 470 in 2011 were selected. The second stage in both surveys involved systematically sampling 25 households for interview in each cluster. Out of 9,842 eligible households, 9,529 were interviewed in 2004 (response rate, $96.1 \%$ ) and in these households 8,830 men completed individual interviews out of 9,905 eligible men (response rate, $89.1 \%$ ). In the 2011 survey, out of 11,434 occupied households, 11,340 were interviewed, giving a response rate of $99.2 \%$. In these households 9,588 men were interviewed out of the 9,983 eligible (response rate, $96 \%)$. In both surveys, eligible respondents were permanent residents of the households or visitors who had spent the survey night in the household. All men 15-59 years were requested to voluntarily provide a blood sample for HIV testing. The response rate for HIV testing was $83.4 \%$ in 2004, and $94.2 \%$ in 2011. This paper is based on information from 14,875 men (6,906 in 2004 and 7,969 in 2011 UAIS) who reported to ever have had sex and had information on HIV status.

\section{Data collection and variables}

Data were collected between August 2004 and January 2005 for the 2004 UAIS and between February and September 2011 for the 2011 UAIS. Both surveys were led by the Uganda Ministry of Health working with ICF international, USA and Uganda Bureau of Statistics. Individual male interviews obtained data on respondents' self-reported circumcision status, their reported sexual behaviours, personal perceived risk of HIV infection, and knowledge of the protection offered by male circumcision against HIV infection (for 2011 alone), and sociodemographic characteristics (age, marital status, highest education level, survey region, ethnicity, residence, religion). Information on wealth status was also obtained from the household interviews and thus reflects the state of the household in which individual men were interviewed. All male interviews were conducted by trained male research assistants.

Laboratory technicians collected blood samples (venous blood or dried blood spots for those who refused venous blood draw) for HIV testing. Tests for the both surveys were conducted at a central laboratory of the Uganda Virus Research Institute using Murex HIV 1.2.0 (Abbott) assay. Samples that were HIV-reactive with Murex were re-tested with Vironostika HIV Uni-Form II Plus-O to confirm their sero-status, while ANILAB Systems HIV enzyme immunoassay was used to resolve discordant results. All the positive specimens and $5 \%$ of the negative specimens were re-tested at the Centers for Disease Control laboratory in Uganda using the same testing algorithm, for quality control purposes. Further details on the tests and quality control are available in the main survey reports [40, 41].

The dependent variables were HIV sero-status obtained from blood sample tests in both surveys, and the following sexual risk behaviours [42] among sexually active circumcised and uncircumcised men: (a) having multiple sexual partners, (b) having had sex with nonmarital partners, (c) non-use of condoms at the last non-marital sex, and (d) transactional sex (payment or receipt of money/gifts in exchange for sex). All these questions referred to behaviours that took place in the 12 months preceding each of the surveys. Condom use at last non-marital sex only included men who reported having such sex. The main independent variable was self-reported circumcision status, while other explanatory variables were socio-demographic characteristics, personal HIV risk perception as well as knowledge of the protection offered by male circumcision against HIV infection (for the 2011 UAIS).

\section{Statistical analyses}

Analyses were conducted using Stata version 13 (StataCorp 2013). Men's individual data files were sorted by unique identifiers to link them to the HIV sero-status data for each survey. Data from the two national surveys were then appended to get one dataset with $14,875 \mathrm{ob}$ servations. A "survey" variable was generated to identify each of the surveys' datasets.

The measure of association used for these analyses were prevalence ratios (PR) and their corresponding $95 \%$ confidence intervals [43-45] obtained via modified Poisson regression models using generalized linear models with 
family (Poisson) and link (log). First we estimated the associations between male circumcision and sexual risk behaviours, or male circumcision and HIV sero-status for each of the surveys. In the adjusted analyses of sexual risk behaviour, socio-demographic characteristics were controlled for. When there was $10 \%$ difference in the survey specific PRs, an interaction term between male circumcision and year of the survey was introduced in combined regression models for each of the sexual risk behaviours to further test if the survey period was important. Sample weights were used in the analyses. We also adjusted for clustering of observations within the same cluster by use of the cluster command in Stata.

\section{Ethical considerations}

Informed consent was obtained before conducting interviews, and separate consent was obtained for taking blood samples. For confidentiality purposes, all personal information that could potentially identify an individual (such as name and address) was destroyed before linking that HIV data to the socio-demographic and behavioural data collected in the individual questionnaires. In the 2004 survey, HIV test results were not provided from the survey but the respondents who wanted to know their HIV status were given a voucher for a free voluntary counselling and testing visit at a nearby health facility or an outreach point established by the survey project [41]. In 2011, home based rapid HIV testing was done and test results were provided on the same day for respondents who wanted to receive them, in addition to the central laboratory tests. Those who tested positive were told to obtain CD4 results six weeks after the interview at a nearby health facility. Counselling was also provided before and after testing by trained counsellors for those who opted to receive results [40].

Each survey protocol was reviewed and approved by the Science and Ethics Committee of the Uganda Virus Research Institute, ICF International's Institutional Review Board, and a review committee at the Centers for Disease Control and Prevention in Atlanta, USA. They were also cleared by the Ethics Committee of the Uganda National Council for Science and Technology. Permission to use both surveys' data was obtained from ICF international, USA, and the Ministry of Health, Uganda.

\section{Results}

\section{Characteristics of respondents}

A total of 14,875 men were analysed in the two surveys. We excluded 531 men from the analysis for this study; sixteen men in 2004 and one in the 2011 survey had indeterminate HIV test results, a further 458 men in 2004 and 51 in 2011 had missing HIV results, and five men in 2004 had missing circumcision status data.
In total 1,792 (26\%) and 2,228 (28 \%) men reported that they were circumcised in 2004 and 2011, respectively. In 2004, two thirds (67\%) of men were married and $86 \%$ lived in rural areas, while in 2011, $72 \%$ were married and $81 \%$ lived in rural areas. The majority (61\% in 2004 and $57 \%$ in 2011) of the men had completed primary education but a higher proportion in 2011 (36\%) had completed secondary or higher education than in 2004 (29 \%). In both surveys, $44 \%$ were from households in the top two wealth quintiles, and the largest ethnic groups were Baganda, Banyankore and Langi/ Acholi. Two thirds (65\%) in 2011 perceived themselves as being at high risk for HIV and $50 \%$ knew that male circumcision reduced the risk of HIV infection to a man.

In 2004, over half of circumcised men (53\%) were from households in the top two wealth quintiles compared to only $44 \%$ of the uncircumcised. Circumcised men were also more educated and more likely to be from urban areas than their uncircumcised counterparts in both surveys. Among the uncircumcised men, $6.8 \%$ in 2004 and $7.8 \%$ in 2011 tested positive for HIV while among the circumcised, 4.3 and $4.8 \%$ in 2004 and 2011, respectively, tested positive.

In 2011, a larger proportion of circumcised than uncircumcised men knew that circumcision was protective (62\% against $46 \%$ ), but the personal perception of HIV risk was similar across both groups (64\% among circumcised, $66 \%$ among the uncircumcised) (Table 1).

\section{Prevalence of sexual risk behaviours}

The prevalence of multiple and non-marital sexual partnerships was stable over the two survey periods. In the 2004 survey, $25 \%$ of men reported sex with multiple partners while in 2011, $22 \%$ reported this behaviour. Thirty five percent of men reported sex with a nonmarital partner in 2004 compared to $33 \%$ in 2011. However, the percentage of men who reported non-use of condoms at the last such sexual intercourse was higher in the 2011 survey (55\% compared to $48 \%$ in 2004). There was an increase in the proportion of men who reported transactional sex from $1.2 \%$ in 2004 to $2.7 \%$ in 2011 (Table 2).

\section{Sexual risk behaviour differences between circumcised and uncircumcised men in 2004 and 2011}

The prevalence of all sexual risk behaviour was higher among the circumcised than the uncircumcised men in both survey periods (Table 2). When we adjusted for socio-demographic variables, circumcision status was significantly associated with having multiple sexual partners both in 2004 and 2011 (2004: adjusted PR 1.38; 95 \% CI 1.26-1.51]; 2011: adjusted PR 1.23; 95 \% CI 1.11-1.36), and having had sex with non-marital sexual partners in 2004 (adjusted PR 1.12; 95 \% CI 1.06-1.20) 
Table 1 Characteristics of circumcised and uncircumcised men 15-59 years, Uganda 2004 and 2011

\begin{tabular}{|c|c|c|c|c|c|c|}
\hline \multirow[t]{2}{*}{ Variables } & \multicolumn{3}{|c|}{2004 UAIS, n (\%) } & \multicolumn{3}{|c|}{2011 UAIS, n (\%) } \\
\hline & Circumcised & Uncircumcised & All men & Circumcised & Uncircumcised & All men \\
\hline \multicolumn{7}{|l|}{ Age } \\
\hline $15-24$ & $492(27.4)$ & $1,318(25.8)$ & $1,809(26.2)$ & $610(27.4)$ & $1,331(23.2)$ & $1,941(24.4)$ \\
\hline $25-34$ & 549 (30.6) & $1,664(32.6)$ & $2,213(32.1)$ & $708(31.8)$ & $1,751(30.5)$ & $2,460(30.9)$ \\
\hline $35-44$ & $434(24.2)$ & $1,162(22.7)$ & $1,596(23.1)$ & $508(22.8)$ & $1,492(26.0)$ & $2,000(25.1)$ \\
\hline $45-59$ & $317(17.7)$ & $970(19.0)$ & $1,288(18.6)$ & $402(18.0)$ & $1,166(20.3)$ & 1,568 (19.7) \\
\hline \multicolumn{7}{|l|}{ Marital status } \\
\hline Never married & $418(23.3)$ & $1,170(22.9)$ & $1,589(23.0)$ & $523(23.5)$ & $1,127(19.6)$ & $1,649(20.7)$ \\
\hline Married & $1,183(66.0)$ & $3,438(67.2)$ & $4,621(66.9)$ & $1,534(68.9)$ & $4,176(72.7)$ & $5,710(71.7)$ \\
\hline Divorced/Widowed & $191(10.6)$ & $506(9.9)$ & $696(10.1)$ & $171(7.7)$ & $438(7.6)$ & $609(7.7)$ \\
\hline \multicolumn{7}{|l|}{ Residence } \\
\hline Urban & 352 (19.6) & $605(11.8)$ & 957 (13.9) & $604(27.1)$ & $916(16.0)$ & $1,520(19.1)$ \\
\hline Rural & $1,440(80.4)$ & $4,509(88.2)$ & $5,949(86.2)$ & $1,624(72.9)$ & $4,825(84.1)$ & $6,449(80.9)$ \\
\hline \multicolumn{7}{|l|}{ Region } \\
\hline Central & $468(26.1)$ & $1,213(23.7)$ & $1,681(24.4)$ & $491(22.0)$ & $1,293(22.5)$ & $1,784(22.4)$ \\
\hline Kampala & 332 (18.6) & $645(12.6)$ & $978(14.2)$ & $215(9.7)$ & $353(6.2)$ & $568(7.1)$ \\
\hline Eastern & $465(25.9)$ & $817(16.0)$ & $1,282(18.6)$ & $882(39.6)$ & 819 (14.3) & $1,701(21.4)$ \\
\hline Northern & $458(25.6)$ & $1,712(33.5)$ & $2,171(31.4)$ & $201(9.0)$ & $1,798(31.3)$ & $1,999(25.1)$ \\
\hline Western & $69(3.8)$ & $725(14.2)$ & $794(11.5)$ & $439(19.7)$ & $1,477(25.7)$ & $1,916(24.1)$ \\
\hline \multicolumn{7}{|l|}{ Highest Education Level } \\
\hline No Education & $164(9.1)$ & $529(10.4)$ & $693(10.1)$ & $143(6.4)$ & $427(7.4)$ & $570(7.2)$ \\
\hline Primary & $1,058(59.1)$ & $3,167(62.0)$ & $4,225(61.3)$ & $1,166(52.3)$ & $3,360(58.5)$ & $4,526(56.8)$ \\
\hline Secondary & $442(24.7)$ & $1,066(20.9)$ & $1,509(21.9)$ & $697(31.3)$ & $1,458(25.4)$ & $2,155(27.0)$ \\
\hline Tertiary & $125(7.0)$ & $342(6.7)$ & $468(6.8)$ & $222(10.0)$ & $496(8.6)$ & $718(9.0)$ \\
\hline \multicolumn{7}{|l|}{ Wealth level } \\
\hline Low & $496(27.7)$ & $1,999(39.1)$ & $2,495(36.1)$ & $654(29.4)$ & $2,297(40.0)$ & $2,952(37.0)$ \\
\hline Middle & $347(19.4)$ & $1,012(19.8)$ & $1,359(19.7)$ & $428(19.2)$ & $1,103(19.2)$ & 1,531 (19.2) \\
\hline High & $949(52.9)$ & $2,103(41.1)$ & $3,052(44.2)$ & $1,146(51.4)$ & $2,341(40.8)$ & $3,486(43.8)$ \\
\hline \multicolumn{7}{|l|}{ Ethnicity } \\
\hline Baganda & $357(19.9)$ & $785(15.4)$ & $1,142(16.6)$ & $400(18.0)$ & $921(16.1)$ & 1,321 (16.6) \\
\hline Banyakore & $68(3.8)$ & $606(11.9)$ & $674(9.8)$ & $109(4.9)$ & $685(11.9)$ & $793(10.0)$ \\
\hline Iteso/Karimojong & $47(2.6)$ & $621(12.2)$ & $668(9.7)$ & $64(2.9)$ & $667(11.6)$ & $730(9.2)$ \\
\hline Lugbara/Madi & $184(10.3)$ & $292(5.7)$ & $477(6.9)$ & $113(5.1)$ & $282(4.9)$ & $396(5.0)$ \\
\hline Basoga & $217(12.1)$ & $416(8.1)$ & $632(9.2)$ & $314(14.1)$ & $401(7.0)$ & $716(9.0)$ \\
\hline Langi/Acholi & $21(1.2)$ & $765(15.0)$ & $786(11.4)$ & $19(0.9)$ & $877(15.3)$ & $896(11.2)$ \\
\hline Bakiga/Bafumbira & $45(2.5)$ & $434(8.5)$ & $479(7.0)$ & $66(2.9)$ & $526(9.2)$ & $592(7.4)$ \\
\hline Bagisu/Sabiny/Bakonzo & $395(22.0)$ & $54(1.1)$ & $449(6.5)$ & $646(29.0)$ & $34(0.6)$ & $680(8.5)$ \\
\hline Alur/Japadhola & $76(4.2)$ & $321(6.3)$ & $397(5.8)$ & $73(3.3)$ & $315(5.5)$ & $387(4.9)$ \\
\hline Banyoro/Batooro & $81(4.5)$ & $323(6.3)$ & $404(5.9)$ & $164(7.4)$ & $516(9.0)$ & $680(8.5)$ \\
\hline Others & $300(16.8)$ & $488(9.6)$ & $788(11.4)$ & $261(11.7)$ & $516(9.0)$ & $777(9.8)$ \\
\hline \multicolumn{7}{|l|}{ Religion } \\
\hline Non Moslem & $931(52.0)$ & $5,085(99.8)$ & $6,016(87.4)$ & $1,202(54.0)$ & $5,729(99.8)$ & $6,931(87.0)$ \\
\hline Moslem & $858(48.0)$ & $12(0.2)$ & $870(12.6)$ & $1,026(46.1)$ & $12(0.2)$ & $1,038(13.0)$ \\
\hline
\end{tabular}


Table 1 Characteristics of circumcised and uncircumcised men 15-59 years, Uganda 2004 and 2011 (Continued)

\begin{tabular}{|c|c|c|c|c|c|c|}
\hline \multicolumn{7}{|l|}{ Perceived HIV risk } \\
\hline Low risk & & & & $743(33.4)$ & $1,721(30.0)$ & $2465(30.9)$ \\
\hline High risk/not sure & & & & $1,431(64.2)$ & $3,772(65.7)$ & $5202(65.3)$ \\
\hline Missing & & & & $54(2.4)$ & $248(4.3)$ & $302(3.8)$ \\
\hline \multicolumn{7}{|c|}{ Knows circumcision Reduces HIV risk } \\
\hline No & & & & $826(37.1)$ & $3,029(52.8)$ & $3855(48.4)$ \\
\hline Yes & & & & $1,389(62.4)$ & $2,634(45.9)$ & $4023(50.5)$ \\
\hline Missing & & & & $13(0.6)$ & $78(1.4)$ & $91(1.1)$ \\
\hline \multicolumn{7}{|l|}{ HIV sero-status } \\
\hline Negative & $1,716(95.7)$ & $4,767(93.2)$ & $6,482(93.9)$ & $2,120(95.2)$ & $5,296(92.3)$ & $7,416(93.1)$ \\
\hline Positive & $76(4.3)$ & $347(6.8)$ & $424(6.1)$ & $108(4.8)$ & $445(7.8)$ & $553(6.9)$ \\
\hline Total & $1,792(100)$ & $5,114(100)$ & $6,906(100)$ & $2,228(100)$ & $5,741(100)$ & 7,969 (100) \\
\hline
\end{tabular}

in the 12 months preceding each survey. There was no difference in 2004 between the two groups regarding condom use at last non-marital sex. However, in 2011, circumcised men were less likely to report use of condoms at the last sex with a non-marital partner than uncircumcised men (adjusted PR 0.85; CI 0.76-0.96). Male circumcision status was not significantly associated with transactional sex in any of the two surveys. Other factors independently associated with sexual risk behaviours were age, marital status, education level, region of residence and wealth quintile of the man's household (Table 3).

There was interaction between the effect of circumcision and age on transactional sex. There was also interaction between the effect circumcision and age on non-marital sex. Circumcision was more strongly associated with these transactional sex among the older (25-59 years) than the younger men (15-24 years). This was also similar for men reporting non-marital sex. Interaction between the effect of circumcision and urban/rural residence on transactional sex was also observed. A slightly higher proportion of circumcised men in the rural areas reported engaging in transactional sex in 2011 than in the 2004 survey. A similar trend was observed among uncircumcised men in urban areas. These stratified results are however based on very few men reporting transactional sex.

The models with combined data from the two surveys with an interaction term for "circumcision status and

Table 2 Prevalence of Sexual risk behaviours among circumcised and uncircumcised men, Uganda 2004 and 2011

\begin{tabular}{|c|c|c|c|c|c|c|}
\hline \multirow[t]{2}{*}{ Variables } & \multicolumn{3}{|c|}{2004 UAIS, n (\%) } & \multicolumn{3}{|c|}{2011 UAIS, n (\%) } \\
\hline & Circumcised & Uncircumcised & All men & Circumcised & Uncircumcised & All men \\
\hline \multicolumn{7}{|c|}{ Had multiple sexual partners } \\
\hline No & $1,201(67.0)$ & $3,996(78.1)$ & $5,196(75.2)$ & $1,615(72.5)$ & $4,572(79.7)$ & $6,187(77.6)$ \\
\hline Yes & $592(33.0)$ & $1,118(21.9)$ & $1,710(24.8)$ & $613(27.5)$ & $1,168(20.4)$ & $1,781(22.4)$ \\
\hline Total & $1,792(100)$ & $5,114(100)$ & $6,906(100)$ & $2,228(100)$ & $5,741(100)$ & $7,969(100)$ \\
\hline \multicolumn{7}{|c|}{ Had transactional sex } \\
\hline No & $1,761(98.2)$ & $5,063(99.0)$ & $6,824(98.8)$ & $2,154(96.7)$ & $5,601(97.6)$ & 7,755 (97.3) \\
\hline Yes & $31(1.8)$ & $51(1.0)$ & $82(1.2)$ & $74(3.3)$ & $139(2.4)$ & $214(2.7)$ \\
\hline Total & $1,792(100)$ & $5,114(100)$ & $6,906(100)$ & $2,228(100)$ & $5,741(100)$ & $7,969(100)$ \\
\hline \multicolumn{7}{|c|}{ Sex with a non-marital partner } \\
\hline No & $926(59.3)$ & $2,951(67.8)$ & $3,878(65.5)$ & $1,229(61.6)$ & $3,569(69.8)$ & $4,798(67.5)$ \\
\hline Yes & $636(40.7)$ & $1,404(32.2)$ & $2,040(34.5)$ & $768(38.5)$ & $1,547(30.2)$ & 2,315 (32.6) \\
\hline Total & $1,562(100)$ & $4,355(100)$ & $5,918(100)$ & $1,997(100)$ & $5,116(100)$ & $7,114(100)$ \\
\hline \multicolumn{7}{|c|}{ Used a condom at last non marital sex } \\
\hline No & $290(45.6)$ & $692(49.3)$ & $983(48.2)$ & $448(58.4)$ & $819(52.9)$ & $1,267(54.7)$ \\
\hline Yes & $346(54.4)$ & $711(50.7)$ & $1,057(51.8)$ & $320(41.6)$ & $728(47.1)$ & $1,048(45.3)$ \\
\hline Total & $636(100)$ & $1,404(100)$ & $2,040(100)$ & $768(100)$ & $1,547(100)$ & $2,315(100)$ \\
\hline
\end{tabular}


Table 3 Generalised linear models showing unadjusted and adjusted associations between sexual risk behaviours and circumcision status among men age 15-59 years, Uganda 2004 and 2011

\begin{tabular}{|c|c|c|c|c|c|c|c|c|}
\hline & \multicolumn{2}{|c|}{$\begin{array}{l}\text { Had multiple sexual partners } \\
\text { in last } 12 \text { months, PR [95 \% Cl] }\end{array}$} & \multicolumn{2}{|c|}{$\begin{array}{l}\text { Had sex with non-marital partner } \\
\text { in last } 12 \text { months, PR [95\% Cl] }\end{array}$} & \multicolumn{2}{|c|}{$\begin{array}{l}\text { Used a condom at last non } \\
\text { marital sex, PR [95 \% Cl] }\end{array}$} & \multicolumn{2}{|c|}{$\begin{array}{l}\text { Transactional sex in last } \\
12 \text { months, PR }[95 \% \mathrm{Cl}]\end{array}$} \\
\hline & 2004 & 2011 & 2004 & 2011 & 2004 & 2011 & 2004 & 2011 \\
\hline \multicolumn{9}{|c|}{$\begin{array}{l}\text { Unadjusted: } \\
\text { Circumcised }\end{array}$} \\
\hline No & 1.0 & 1.0 & 1.0 & 1.0 & 1.0 & 1.0 & 1.0 & 1.0 \\
\hline Yes & $1.51^{*}[1.38,1.65]$ & $1.35^{*}[1.23,1.49]$ & $1.26^{*}[1.17,1.37]$ & $1.27^{*}[1.17,1.38]$ & $1.07[0.98,1.18]$ & $0.88^{*}[0.79,0.99]$ & $1.72[1.06,2.81]$ & $1.36[0.99,1.88]$ \\
\hline \multicolumn{9}{|c|}{$\begin{array}{l}\text { Adjusted }{ }^{\mathrm{a}} \text { : } \\
\text { Circumcised }\end{array}$} \\
\hline No & 1.0 & 1.0 & 1.0 & 1.0 & 1.0 & 1.0 & 1.0 & 1.0 \\
\hline Yes & $1.38^{*}[1.26,1.51]$ & $1.23^{*}[1.11,1.36]$ & $1.12^{*}[1.06,1.20]$ & $1.05[0.99,1.13]$ & $1.00[0.92,1.10]$ & $0.85^{*}[0.76,0.96]$ & $1.56[0.92,2.62]$ & $1.23[0.85,1.76]$ \\
\hline $\begin{array}{l}\text { Number } \\
\text { of men }\end{array}$ & 6886 & 7857 & 5919 & 6996 & 1945 & 2233 & 6886 & 7857 \\
\hline
\end{tabular}

${ }^{a}$ Adjusted for highest education level, Age, Marital status, Survey region, Residence, and Wealth status ${ }^{*} p<0.05$

survey period" indicate that non-use of condoms at the last non-marital sex among circumcised men significantly varied by survey. There was a reduction in condom use in 2011, with circumcised men significantly less likely to report use. The association between circumcision and multiple sexual partners did not significantly vary between 2004 and 2011 (Table 4).

\section{Male circumcision and HIV sero-status}

Male circumcision was significantly associated with lower HIV prevalence across both surveys. After adjusting for background characteristics, circumcised men were $43 \%$ less likely to test HIV positive in 2004 (adjusted PR 0.57; CI 0.44-0.75) and $34 \%$ less likely in the 2011 UAIS (adjusted PR 0.66; CI 0.51-0.84) compared to the uncircumcised. The PRs did not change substantially after including sexual risk behaviours in the models (Table 5).

\section{Discussion}

Circumcised men reported higher prevalence of all sexual risk behaviours examined, except for transactional sex, than uncircumcised men. Use of condoms with the last non-marital sexual partner among circumcised men reporting non-marital sex was lower in 2011 compared with 2004. However, there was no significant change in the prevalence of other sexual risk behaviours between the two survey periods. Thus we conclude that there is limited evidence to support our hypothesis from the two UAISs. Even with higher reported prevalence of sexual risk behaviours, circumcised men were less likely to test HIV positive than the uncircumcised in both surveys.

It is plausible that the reduction in condom use among circumcised men could be linked to risk compensation due to higher awareness in 2011 that circumcision was protective since a similar reduction in reported condom

Table 4 Models of the associations between sexual risk behaviours and circumcision status with combined data from the 2004 and 2011 UAIS

\begin{tabular}{|c|c|c|c|c|}
\hline & \multicolumn{2}{|c|}{ Had multiple sexual partners in last 12 months } & \multicolumn{2}{|c|}{ Used a condom at last non marital sex } \\
\hline & Unadjusted, & Adjusted, & Unadjusted, & Adjusted, \\
\hline & PR $[95 \%$ Cl] & PR $[95 \% \mathrm{Cl}]$ & PR $[95 \% \mathrm{Cl}]$ & PR $[95 \% \mathrm{Cl}]$ \\
\hline \multicolumn{5}{|l|}{ Circumcised $^{a}$} \\
\hline No & 1.0 & 1.0 & 1.0 & 1.0 \\
\hline Yes & $1.51^{*}[1.37,1.66]$ & $1.42^{*}[1.29,1.56]$ & $1.07[0.96,1.20]$ & $1.02[0.93,1.12]$ \\
\hline \multicolumn{5}{|l|}{ Survey } \\
\hline 2004 UAIS & 1.0 & 1.0 & 1.0 & 1.0 \\
\hline 2011 UAIS & $0.93[0.84,1.03]$ & $0.92[0.83,1.02]$ & $0.93[0.84,1.03]$ & $0.99[0.91,1.07]$ \\
\hline Interaction term (circumcision and survey) & $0.90[0.77,1.04]$ & $0.89[0.77,1.03]$ & $0.82^{*}[0.70,0.97]$ & $0.81^{*}[0.71,0.93]$ \\
\hline Number of men & 14757 & 14743 & 4181 & 4178 \\
\hline
\end{tabular}

${ }^{a}$ Adjusted for highest education level, Age, Marital status, Survey region, Residence, and Wealth status ${ }^{*} p<0.05$ 
Table 5 Generalised linear models showing unadjusted and adjusted associations between circumcision status and HIV test results among circumcised and uncircumcised men age 15-59 years, Uganda 2004 and 2011

\begin{tabular}{|c|c|c|c|c|c|}
\hline (1) & (2) & (3) & (4) & (5) & (6) \\
\hline $\begin{array}{l}\text { Unadjusted: Tested } \\
\text { HIV positive, } 2004 \\
\text { PR ( } 95 \% \text { CI) }\end{array}$ & $\begin{array}{l}\text { Unadjusted: Tested } \\
\text { HIV positive, } 2011 \\
\text { PR (95\% Cl) }\end{array}$ & $\begin{array}{l}\text { Adjusted for } \\
\text { background } \\
\text { characteristics }{ }^{\text {a. }} \text { : } \\
\text { Tested HIV positive, } \\
2004 \text { PR ( } 95 \% \text { Cl) }\end{array}$ & $\begin{array}{l}\text { Adjusted for } \\
\text { background } \\
\text { characteristics }{ }^{\text {a. }} \text { : } \\
\text { Tested HIV positive, } \\
2011 \text { PR (95\% Cl) }\end{array}$ & $\begin{array}{l}\text { Adjusted for } \\
\text { background } \\
\text { characteristics } \\
\text { and sexual risk } \\
\text { behaviours } \\
\text { Tested HIV positive, } \\
2004 \text { PR ( } 95 \% \text { Cl) }\end{array}$ & $\begin{array}{l}\text { Adjusted for } \\
\text { background } \\
\text { characteristics } \\
\text { and sexual } \\
\text { risk behaviours } \\
\text { Tested HIV } \\
\text { positive, } 2011 \\
\text { PR }(95 \% \text { Cl) }\end{array}$ \\
\hline 1.0 & 1.0 & 1.0 & 1.0 & 1.0 & 1.0 \\
\hline $0.63^{*}[0.48,0.82]$ & $0.62^{*}[0.49,0.80]$ & $0.57^{*}[0.44,0.75]$ & $0.66^{*}[0.51,0.84]$ & $0.55^{*}[0.41,0.73]$ & $0.64^{*}[0.49,0.83]$ \\
\hline 6900 & 7857 & 6886 & 7857 & 5919 & 6996 \\
\hline
\end{tabular}

\begin{tabular}{|c|c|c|c|c|c|c|}
\hline \multicolumn{7}{|l|}{ Circumcised } \\
\hline No & 1.0 & 1.0 & 1.0 & 1.0 & 1.0 & 1.0 \\
\hline Yes & $0.63^{*}[0.48,0.82]$ & $0.62^{*}[0.49,0.80]$ & $0.57^{*}[0.44,0.75]$ & $0.66^{*}[0.51,0.84]$ & $0.55^{*}[0.41,0.73]$ & $0.64^{*}[0.49,0.83$ \\
\hline Number of men & 6900 & 7857 & 6886 & 7857 & 5919 & 6996 \\
\hline
\end{tabular}

use at the last non-marital sex was not found among uncircumcised men. Since condoms are even more effective against heterosexual HIV infection than circumcision $[46,47]$, a reduction in their use because of male circumcision [48] would be a dangerous 'trade off'. Inconsistent condom use after circumcision has been associated with increased risk of HIV infection among young men in eastern Uganda [49]. This could significantly reduce the beneficial effect of circumcision against HIV infection, even with its reported high efficacy levels $[21,50]$.

Circumcised men reported higher prevalence of multiple sexual partners in both 2004 and 2011 than the uncircumcised. Although there were no significant differences in the association over time, i.e. indicating that any risk compensation due to the SMC campaign was limited at this early stage of the campaign, multiple sexual partnerships coupled with higher prevalence of non-use of condoms in 2011 is a potentially dangerous situation if it continues uncontrolled. If persons who have multiple sexual relationships also have concurrent partners, non-use of condoms is particularly risky because HIV infection can easily spread to several persons in the sexual network if one of the concurrent partners are newly infected (and thus more infectious) [51, 52]. Concurrency has been one of the main drivers of heterosexual HIV infections in sub Saharan Africa in the past decades $[1,53,54]$.

Further, because of the early stages of the SMC campaign, it is possible that some previously circumcised men may not have fully understood partial risk reduction as opposed to eliminating the entire risk of HIV infection, leading to a misguided sense of sexual freedom [48]. These two concepts may still be hard for the population to understand fully even in the current stage of the campaign, a challenge that could further be complicated by appropriate translation into all local dialects for diverse populations ([55], p.26). It may be hard to convince all circumcised men as well as their sexual partners to continue using condoms after circumcision, even when engaging in high risk behaviours such as multiple sexual partnerships. However, if such behaviour continues unabated in the current 'mature' period of the SMC programme, this should have implications for circumcision-related social marketing messages that mainly focus on those intending to circumcise, and less on behaviours of men already circumcised.

Although a higher occurrence of sexual risk behaviours was reported among circumcised men, the HIV prevalence was significantly lower among this group than the uncircumcised in both 2004 and 2011 survey. The associations remained significant even after adjusting for sexual risk behaviours in the final model. Higher sexual risk behaviours among circumcised men did not seem to affect their HIV risk. This further supports the evidence for protection that male circumcision offers against HIV infection [3, 6-8]. However, caution needs to be consistently publicly re-echoed to ensure circumcised men embrace safer sexual behaviours even with knowledge that the intervention is protective.

The study has several limitations. First, the cross sectional nature of both surveys means inability to ascertain temporality and causation between circumcision, sexual behaviour and HIV status. Second, both circumcision status and the sexual risk behaviours were obtained using individual men's self-reports in face-to-face interviews which can be liable to social desirability [56] as well as recall biases when reporting for a 12 months periods. However, all the individual interviews were conducted by well-trained male interviewers using standardised questionnaires. The results from this study are from nationally representative samples of men with a high response rate and can be generalised to the general adult male 
population in Uganda. The surveys are also drawn using the same standard sampling methodology from a similar target population 5 years apart. Even though they are not panel surveys, they can be comparable across the time points.

\section{Conclusions}

This study indicates higher prevalence of sexual risk behaviours among circumcised men in each survey and lower prevalence in use of condoms with non-marital sexual partners among circumcised men in 2011, suggesting possible risk compensation among some circumcised men. However, even with higher prevalence of sexual risk behaviours, circumcised men still had significantly lower HIV prevalence than their uncircumcised counterparts. Considering the high levels of sexual risk behaviours among men who are already circumcised observed in this study, the Ministry of Health and partners need to continue sensitising the sexually active population to use condoms especially when having multiple sexual partners, even when a man is circumcised. These messages should target both circumcised men and their sexual partners. Educating men undergoing circumcision also needs to be strengthened to avoid sexual risk taking post circumcision.

\section{Competing interests}

The authors declare that they have no competing interests.

\section{Authors' contributions}

SPSK conceived the study, led the data analysis and drafting of the manuscript. IFS and FM significantly contributed to the data analysis and writing of the manuscript. MD and LMA significantly contributed to writing and revising the manuscript. All authors read and approved the final manuscript.

\section{Authors' information \\ SPSK is a doctoral student at the centre for international health, University of Bergen, Norway, and an assistant lecturer at the department of community health and behavioural sciences, school of public health, Makerere University. IFS is an associate professor of epidemiology at the centre for international health, department of global public health and primary care, faculty of medicine and dentistry, University of Bergen, Norway. \\ $\mathrm{MD}$ is an associate professor at the department of health promotion and development, faculty of psychology, University of Bergen, Norway. LMA is an associate professor at the department of community health and behavioural sciences, school of public health, Makerere University, Uganda FM is a biostatistician and associate professor at the department of epidemiology and biostatistics, school of public health, Makerere University, Uganda.}

\section{Acknowledgements}

This work was supported by a scholarship to the first author from the Norwegian State Education Loan Fund (Statens lånekasse), the University of Bergen, Norway and Makerere University, Uganda. The funders had no role in the conducting the study. We are also grateful to ICF International and Uganda Ministry of Health that provided access to the AIDS Indicator surveys datasets used in this study.

\section{Author details}

${ }^{1}$ Centre for International Health, Department of Global Public Health and Primary Care, Faculty of Medicine and Dentistry, University of Bergen, Bergen, Norway. ${ }^{2}$ Department of Community Health and Behavioural Sciences, School of Public Health, Makerere University, Kampala, Uganda. ${ }^{3}$ Department of Health Promotion and Development, Faculty of Psychology, University of Bergen, Bergen, Norway. ${ }^{4}$ Department of Epidemiology and Biostatistics, School of Public Health, Makerere University, Kampala, Uganda.
Received: 13 October 2015 Accepted: 21 December 2015

Published online: 05 January 2016

\section{References}

1. Wanyama OJ, Kaweesa KD, Kirungi W, Odiit M, Wabwire-Mangen F. Uganda HIV prevention response and modes of transmission analysis. Kampala: Uganda national AIDS commission, UNAIDS. 2009.

2. UNAIDS. The GAP report. Geneva: Joint United Nations Programme on HIV/AIDS; 2014

3. Siegfried N, Muller M, Volmink J, Deeks J, Egger M, Low N, et al. Male circumcision for prevention of heterosexual acquisition of HIV in men Cochrane Database Syst Rev. 2003;3:CD003362. doi:10.1002/14651858. CD003362.

4. Auvert B, Buve A, Ferry B, Carael M, Morison L, Lagarde E, et al. Ecological and individual level analysis of risk factors for HIV infection in four urban populations in sub-Saharan Africa with different levels of HIV infection. AIDS (London, England). 2001;15(4):S15-30.

5. Weiss HA, Quigley MA, Hayes RJ. Male circumcision and risk of HIV infection in sub-Saharan Africa: a systematic review and meta-analysis. AIDS (London, England). 2000;4(15):2361-70.

6. Gray RH, Kigozi G, Serwadda D, Makumbi F, Watya S, Nalugoda F, et al. Male circumcision for HIV prevention in men in Rakai, Uganda: a randomised trial. Lancet. 2007;369(9562):657-66. doi:10.1016/S0140-6736(07)60313-4. S0140-6736(07)60313-4 [pii]

7. Bailey RC, Moses S, Parker CB, Agot K, Maclean I, Krieger JN, et al. Male circumcision for HIV prevention in young men in Kisumu, Kenya: a randomized controlled trial. Lancet. 2007;369(9562):643-56.

8. Auvert B, Taljaard D, Lagarde E, Sobngwi-Tambekou J, Sitta R, Puren A. Randomized, controlled intervention trial of male circumcision for reduction of HIV infection risk: the ANRS 1265 Trial. PLoS Med. 2005; 2(11):e298. doi:10.1371/journal.pmed.0020298.

9. Auvert B, Sobngwi-Tambekou J, Cutler E, Nieuwoudt M, Lissouba P, Puren A, et al. Effect of male circumcision on the prevalence of high-risk human papillomavirus in young men: results of a randomized controlled trial conducted in Orange Farm, South Africa. Am J Infect Dis. 2009;199(1):14-9. doi:10.1086/595566.

10. Tobian AA, Serwadda D, Quinn TC, Kigozi G, Gravitt PE, Laeyendecker O, et al. Male circumcision for the prevention of HSV-2 and HPV infections and syphilis. N Engl J Med. 2009;360(13):1298-309. doi:10.1056/NEJMoa0802556.

11. Wawer MJ, Tobian AA, Kigozi G, Kong X, Gravitt PE, Serwadda D, et al. Effect of circumcision of HIV-negative men on transmission of human papillomavirus to HIV-negative women: a randomised trial in Rakai. Uganda Lancet. 2011;377(9761):209-18. doi:10.1016/S0140-6736(10)61967-8.

12. Nurminen M. On the epidemiologic notion of confounding and confounder identification. Scand J Work Environ Health. 1997;23(1):64-8.

13. WHO/UNAIDS. New data on male circumcision and HIV prevention: policy and programme implications. Geneva: World Health Organisation and Joint United Nations Programme on HIV/AIDS; 2007.

14. WHO/UNAIDS. Joint strategic action framework to accelerate the scale-Up of voluntary medical male circumcision for HIV prevention in eastern and southern africa 2012-2016: world health organisation and joint united nations programme on HIV/AIDS. 2011

15. Center for Communication Programs. The health communication partnership Uganda, final report. Kampala: Johns Hopkins Bloomberg School of Public Health CCP; 2012.

16. MOH. Safe male circumcision policy. Kampala: Uganda: Ministry of Health; 2010.

17. MOH. Safe male circumcision for HIV prevention. National communication strategy. Kampala: Uganda: Ministry of Health; 2010.

18. Uganda AIDS Commission. HIV and AIDS Uganda country progress report. Kampala: Uganda: UAC; 2013

19. WHO. Global update on the health sector response to HIV. Geneva: Switzerland World Health Organization; 2014.

20. WHO UNAIDS and UNICEF. Global HIV/AIDS Response: Epidemic update and health sector progress towards Universal Access. Progress report2011

21. Hallett TB, Singh K, Smith JA, White RG, Abu-Raddad L, Garnett GP. Understanding the impact of male circumcision interventions on the spread of HIV in southern Africa. PLoS One. 2008:3(5):e2212. doi:10.1371/journal. pone.0002212.

22. Adams J, Hillman M. The risk compensation theory and bicycle helmets, Inj Prev. 2001;7(4):343. 
23. Riess HT, Achieng MM, Otieno S, Ndinya-Achola JO, Bailey CR. "When I was circumcised I was taught certain things": risk compensation and protective sexual behavior among circumcised Men in kisumu, Kenya. PLoS One. 2010;5(8):1-9. doi:10.1371/journal.pone.0012366.

24. Hedlund J. Risky business: safety regulations, risk compensation, and individual behavior. Inj Prev. 2000;6:82-90.

25. Hogben M, Liddon N. Disinhibition and risk compensation: scope, definitions, and perspective. Sex Transm Dis. 2008;35(12):1009-10. doi:10.1097/OLQ.0b013e31818eb752.

26. Cassell MM, Halperin DT, Shelton JD, Stanton D. Risk compensation: the Achilles' heel of innovations in HIV prevention? Bmj. 2006;332(7541):605-7. doi:332/7541/605 [pii] 10.1136/bmj.332.7541.605.

27. Eaton L, Kalichman SC. Behavioral aspects of male circumcision for the prevention of HIV infection. Curr HIV/AIDS Rep. 2009;6(4):187-93.

28. Abbott SA, Haberland NA, Mulenga DM, Hewett PC. Female sex workers, male circumcision and HIV: a qualitative study of their understanding, experience, and HIV risk in Zambia. PLoS One. 2013;8(1):e53809. doi:10.1371/journal.pone.0053809.

29. Layer EH, Beckham SW, Momburi RB, Kennedy CE. Understanding the partial protection of male circumcision for HIV prevention among women in Iringa Region, Tanzania: an ethnomedical model. AIDS care. 2013;25(8):1045-50. doi:10.1080/09540121.2012.748874.

30. Kembabazi A, Bajunirwe F, Hunt PW, Martin JN, Muzoora C, Haberer JE, et al. Disinhibition in risky sexual behavior in men, but not women, during 4 years of antiretroviral therapy in rural, southwestern Uganda. PLoS One. 2013;8(7):e69634. doi:10.1371/journal.pone.0069634.

31. Sensalire S. Cross sectional cohort study to assess behavioral disinhibition following Antiretroviral Therapy (ART). 6th IAS conference on HIV pathogenesis, prevention and treatment; 17-20 July. Rome, Italy: International AIDS Society; 2011.

32. Andersson KM, Vardas E, Niccolai LM, Van Niekerk RM, Mogale MM, Holdsworth $I M$, et al. Anticipated changes in sexual risk behaviour following vaccination with a low-efficacy HIV vaccine: survey results from a South African township. Int J STD AIDS. 2012;23(10):736-41. doi:10.1258/ijsa.2009.009378.

33. Newman PA, Lee SJ, Duan N, Rudy E, Nakazono TK, Boscardin J, et al. Preventive HIV vaccine acceptability and behavioral risk compensation among a random sample of high-risk adults in Los Angeles (LA VOICES). Health Serv Res. 2009;44(6):2167-79. doi:10.1111/j.1475-6773.2009.01039.x.

34. Newman PA, Roungprakhon S, Tepjan S, Yim S. Preventive HIV vaccine acceptability and behavioral risk compensation among high-risk men who have sex with men and transgenders in Thailand. Vaccine. 2010;28(4):958-64. doi:10.1016/j.vaccine.2009.10.142.

35. Kong X, Kigozi G, Nalugoda F, Musoke R, Kagaayi J, Latkin C, et al. Assessment of changes in risk behaviors during 3 years of posttrial follow-up of male circumcision trial participants uncircumcised at trial closure in Rakai, Uganda. Am J Epidemiol. 2012;176(10):875-85. doi:10.1093/aje/kws179.

36. Agot KE, Kiarie JN, Nguyen HQ, Odhiambo JO, Onyango TM, Weiss NS. Male circumcision in Siaya and Bondo Districts, Kenya: prospective cohort study to assess behavioral disinhibition following circumcision. Journal of acquired immune deficiency syndromes (1999). 2007;44(1):66-70. doi:10.1097/01.qai. 0000242455.05274 .20 .

37. Ayiga N, Letamo G. Impact of male circumcision on HIV risk compensation through the impediment of condom use in Botswana. Afr Health Sci. 2011;11(4):550-9.

38. Westercamp N, Agot K, Jaoko W, Bailey RC. Risk compensation following male circumcision: results from a 2 year prospective cohort study of recently circumcised and uncircumcised men in Nyanza province. Kenya AIDS and behavior. 2014;18(9):1764-75. doi:10.1007/s10461-014-0846-4.

39. Kibira SP, Nansubuga E, Tumwesigye NM, Atuyambe LM, Makumbi F. Differences in risky sexual behaviors and HIV prevalence of circumcised and uncircumcised men in Uganda: evidence from a 2011 cross-sectional national survey. Reprod Health. 2014;11(1):25. doi:10.1186/1742-4755-11-25.

40. $\mathrm{MOH}$ and ICF International. Uganda AIDS indicator survey. Kampala: Uganda and Calverton Maryland, USA: Ministry of Health and ICF International2012; 2011.

41. MOH and ORC Macro. Uganda HIV/AIDS sero-behavioural survey 2004-2005. Calverton: Maryland, USA: Ministry of Health and ORC Macro; 2006.

42. UNAIDS. National AIDS Programmes: A Guide to Monitoring and Evaluation. Geneva, Switzerland: Joint United Nations Programme on HIV/AIDS2000 June. Report No.: UNAIDS/00.17E
43. Zocchetti C, Consonni D, Bertazzi PA. Relationship between prevalence rate ratios and odds ratios in cross-sectional studies. Int J Epidemiol. 1997;26(1):220-3.

44. Traissac P, Martin-Prevel Y, Delpeuch F, Maire B. Logistic regression vs other generalized linear models to estimate prevalence rate ratios. Rev Epidemiol Sante Publique. 1999;47(6):593-604.

45. Barros AJ, Hirakata VN. Alternatives for logistic regression in cross-sectional studies: an empirical comparison of models that directly estimate the prevalence ratio. BMC Med Res Methodol. 2003;3:21. doi:10.1186/1471-2288-3-21.

46. Pinkerton SD, Abramson PR. Effectiveness of condoms in preventing HIV transmission. Soc Sci Med. 1997:44(9):1303-12.

47. Weller S, Davis K. Condom effectiveness in reducing heterosexual HIV transmission. Cochrane Database Syst Rev. 2001;3:CD003255. doi:10.1002/14651858.CD003255.

48. Grund JM, Hennink MM. A qualitative study of sexual behavior change and risk compensation following adult male circumcision in urban Swaziland. AIDS care. 2012;24(2):245-51. doi:10.1080/09540121.2011.596516.

49. Ediau M, Matovu JK, Byaruhanga R, Tumwesigye NM, Wanyenze RK. Risk factors for HIV infection among circumcised men in Uganda: a case-control study. J Int AIDS Soc. 2015;18(1):19312. doi:10.7448/IAS.18.1.19312.

50. Gray RH. Reducing HIV transmission: lessons from rakai and other African studies. International AIDS society. Rio de Janeiro, Brazil: Reported in UNAIDS and WHO (2007) Male circumcision: global trends and determinants of prevalence, safety and acceptability. WHO/UNAIDS; 2005.

51. Eaton JW, Hallett TB, Garnett GP. Concurrent sexual partnerships and primary HIV infection: a critical interaction. AIDS Behav. 2011;15(4):687-92. doi:10.1007/s10461-010-9787-8

52. Pilcher CD, Tien HC, Eron Jr JJ, Vernazza PL, Leu SY, Stewart PW, et al. Brief but efficient: acute HIV infection and the sexual transmission of HIV. Asian J Infect Dis. 2004;189(10):1785-92. doi:10.1086/386333.

53. Morris M, Epstein $\mathrm{H}$, Wawer M. Timing is everything: international variations in historical sexual partnership concurrency and HIV prevalence. PLoS One. 2010;5(11):e14092. doi:10.1371/journal.pone.0014092.

54. Mishra V, Simona B-VA. Concurrent sexual partnerships and HIV infection: evidence from national population-based surveys. DHS working papers No. 62. Calverton, Maryland: Macro International Inc; 2009.

55. WHO and UNAIDS. Male circumcision: global trends and determinants of prevalence, safety and acceptability. Geneva: World Health Organization, United Nations Joint Programme on HIV/AIDS and London School of Hygiene and Tropical Medicine; 2007.

56. Kelly CA, Soler-Hampejsek E, Mensch BS, Hewett PC. Social desirability bias in sexual behavior reporting: evidence from an interview mode experiment in rural Malawi. Int Perspect Sex Reprod Health. 2013;39(1):14-21. doi:10.1363/3901413.

\section{Submit your next manuscript to BioMed Central and we will help you at every step:}

- We accept pre-submission inquiries

- Our selector tool helps you to find the most relevant journal

- We provide round the clock customer support

- Convenient online submission

- Thorough peer review

- Inclusion in PubMed and all major indexing services

- Maximum visibility for your research

Submit your manuscript at www.biomedcentral.com/submit 